\title{
Penile Cancer pT0 TNM Finding v7
}

National Cancer Institute

\section{Source}

National Cancer Institute. Penile Cancer pTO TNM Finding v7. NCI Thesaurus. Code C89167.

Penile cancer with no evidence of a primary tumor. (from AJCC 7th Ed.) 